\title{
CONFLICTOS DE PODER EN EL TUCUMÁN HISPANO: ALONSO DE RIBERA Y EL OBISPO HERNANDO DE TREJO Y SANABRIA (1606-1611)
}

\author{
Daniela Alejandra Carrasco \\ (Universidad Nacional de Salta-Argentina)
}

\section{RESUMEN}

En este trabajo expondremos sobre el sistema de gobierno de la Monarquía Hispana en relación a una de sus regiones alejadas del centro político, la Gobernación del Tucumán. Nos centraremos en el gobierno de Alonso de Ribera (1606-1611), destacando su gestión en el marco de las políticas planteadas para América por Felipe III y su valido el duque de Lerma, e instrumentalizadas por el Conde de Lemos. Asimismo, estudiaremos el rol político desempeñado por el obispo del Tucumán don Hernando de Trejo y Sanabria y los enfrentamientos que tuvo con el gobernador.

PALABRAS CLAVE: Monarquía Hispana; Gobernación del Tucumán; proyecto político; élite local; enfrentamientos de poder.

\section{CONFLICTS OF POWER IN THE HISPANIC TUCUMÁN: ALONSO DE RIBERA AND BISHOP HERNANDO DE TREJO Y SANABRIA (1606-1611)}

\begin{abstract}
In this work we will be exhibited on the system of government of the Hispanic Monarchy in relation to one of its regions far from the political center, the Governorate of Tucumán. We will focus on the government of Alonso de Ribera (1606-1611), highlighting its management within the framework of the politics raised for America by Felipe III and his favorite the duke of Lerma, and manipulated by the count of Lemos. Also, there will be studied the political role played by the bishop of the Tucumán don Hernando de Trejo y Sanabria, and the clashes that had with the governor.
\end{abstract}

KEYWORDS: Hispanic Monarchy; Governorship of Tucumán; political project; local elite; confrontation of power 
La dinámica expansiva y expulsiva de las gobernaciones durante el siglo XVI planteó la necesidad de crear nuevas "provincias"1, para satisfacer las demandas sociales de los excluidos y de un proyecto político a escala de imperio. En ese sentido, desde el Perú, tanto partidarios almagristas como pizarristas, manifestaron la necesidad de ensayar caminos hacia la ruta atlántica, tal cual afirmaba el principio proclamado por Juan Ortiz de Zárate: «asegurar lo existente, fundar en el intermedio»². Dentro de ese contexto debemos ubicar la creación de la Gobernación del Tucumán en 1563, a quien siete años después se le dio un obispado con idénticos límites territoriales ${ }^{3}$. Esta gobernación se ubicaba en lo que se conoce como el actual noroeste argentino, abarcando las provincias de Jujuy, Salta, Catamarca, La Rioja, Córdoba, Tucumán y Santiago del Estero, que ocupaba en aquel entonces unos 700.000 kilómetros cuadrados con ocho incipientes ciudades, la cual Santiago del Estero era considerada cabecera y residencia de las autoridades ${ }^{4}$.

La Gobernación dependía jurisdiccionalmente del Virreinato del Perú, y dentro de él, de la Audiencia de Charcas. Con el descubrimiento en 1545 de minerales de plata en Potosí, el Alto Perú o Charcas comenzó a adquirir suma importancia. De este modo, la ciudad de La Plata, capital y sede de la Audiencia, fue quien mantuvo la dominación jurisdiccional sobre el Tucumán por Real Cédula desde $1563^{5}$. Del mismo modo, en la organización religiosa el obispado del Tucumán era dependiente del arzobispado de Charcas, elevada a Sede metropolitana en 1609 (anteriormente dependía del arzobispado de Lima) ${ }^{6}$.

\footnotetext{
${ }^{1}$ No empleamos el término provincia, presente en la documentación de la época, con su carga conceptual actual, sino que la consideramos como un espacio jurisdiccional, siendo más preciso hablar de gobernación. En efecto, la voz provincia parecía seguir en su uso indiano el modelo romano, que llevaba implícita la noción de distancia, que separaba lejanas comarcas del centro del poder político. Por lo tanto, podemos observar que las provincias indianas eran consideradas institucionalmente equiparable a otros territorios de la Monarquía, incluso reinos y provincias peninsulares. Ver Zakarías Moutoukias, “Gobierno y Sociedad en el Tucumán y el Río de la Plata, 1550-1800”, en Nueva Historia Argentina. La sociedad colonial, Enrique Tandeter dir., (Buenos Aires: Sudamericana, 2000), t. II., 216.

${ }^{2}$ Darío Barriera, Abrir puertas a la tierra, Microanálisis de la construcción de un espacio político, Santa Fe, 1573 1640, (Santa Fe: Ministerio de Innovación y Cultura de la Provincia de Santa Fe, Museo Histórico Provincial Brigadier Estanislao López, 2017 [2013]), 100-101. Sobre la conquista y fundación de las ciudades del Tucumán podemos citar algunos ejemplos: Roberto Levillier, Descubrimiento y Población del Norte Argentino por españoles del Perú. Desde la entrada al Tucumán hasta la fundación de Santiago del Estero, 15431553, (Buenos Aires, 1943); Manuel Lizondo Borda, Historia de la Gobernación del Tucumán, siglo XVI, (Buenos Aires, Imprenta y Editora de Coni Hermanos, 1928).

3 Por la bula Super specula del 15 de mayo de 1570, Pio V había erigido como diócesis al Tucumán, con sede en la ciudad de Santiago del Estero, Véase Nelson Dellaferrera, "Iglesia diocesana: Las instituciones", en Nueva Historia de la Nación Argentina, (Buenos Aires: Planeta, 1999), t. II, 397-198.

4 Vicente Sierra, "La Gobernación del Tucumán desde 1600 a 1619”, en Historia de la Argentina. Bajo el Reinado de Felipe III. Libro I, (Bs. As.: Editorial Científica Argentina, 1957), 61.

${ }^{5}$ Real Cédula de Felipe II del 29 de agosto de 1563, reproducida por Ricardo Freyre, El Tucumán colonial. Documentos y mapas del archivo de Indias, (Buenos Aires, Coni Hermanos, 1915), 43.

${ }^{6}$ Antonio García y García, "La organización territorial de la Iglesia", en La historia de la Iglesia en Hispanoamérica y Filipinas, vol. I: Aspectos generales, Pedro Borges, (Madrid: Biblioteca de Autores cristianos, 1992), 140.
} 
El Tucumán no poseía las mismas riquezas mineras que los Andes Centrales por lo tanto se produjo un desarrollo en la explotación agrícola, ganadera y textil. Este género de economía favoreció el avance de la llamada encomienda de servicio basado en el sistema de explotación de la mano de obra indígena ${ }^{7}$. Ellos trabajaban la tierra a modo de servicio personal para una élite local que se consolidó en la primera mitad del siglo XVII. Hay que destacar que los encomenderos del Tucumán gozaron de una mayor libertad y autonomía que sus pares peruanos, como consecuencia de la pobreza relativa de recursos, sumada a la presencia de la permanente guerra contra los indígenas no sometidos (nos referimos a la población indígena que no se incorporó al dominio español sino hasta mediados del siglo XVII en la Quebrada de Humahuaca, la Puna de Jujuy y los Valles Calchaquíes) ${ }^{8}$. Por otra parte, dicha élite no sólo era propietaria de encomiendas y enormes superficies de tierras en forma de solares, quintas, chacras y estancias, sino que además gozaron en general de la condición de hidalgos, y a medida que reforzaban su condición de vecinos pretendían mayores derechos de participación en el gobierno comunal. En este sentido, los vecinos encomenderos, a pesar de mostrar rasgos señoriales, no conformaron una "aristocracia ociosa", sino más bien, formaron parte de la minoría dirigente y empresaria en el contexto de una economía de cambio activado por el centro minero potosino?

No parece un dato menor que Ricardo Freyre afirme que las rentas de los vecinos del Tucumán estaban constituidas exclusivamente por la venta de ganado, de «algunos preciosos productos agrícolas» y de tejidos de algodón, que alcanzaban buenos precios en Charcas y Potosí, y recibían a cambio los «efectos de Castilla» ${ }^{10}$. El mismo gobernador Alonso de Ribera en una carta escrita a Felipe III informaba que las

granjerías de esta tierra son lienzos, alpargatas, calcetas, sobremesas, sobrecamas, pellones, pavilo para hacer velas, algunos sombreros y pocos cordobanes y badanas, mulas y ganado mayor». Parte de estos productos se dirigían a Chile, y el resto al Alto Perú. Ribera añadía que «hallan plata por ellos, e llegando con que se proveen de lo que an menester para sus cassas y hallan crédito de diez y doce y veinte mil pesos para retornos de ropa de castilla

\footnotetext{
${ }^{7}$ Para profundizar sobre el régimen de encomiendas en el Tucumán ver Gastón Doucet, "En torno a la población aborigen y a las encomiendas de indios del antiguo Tucumán”, Revista de Indias, 47 (1987): 253-313.

${ }^{8}$ Raquel Gil Montero "La población del Tucumán colonial”, Cuadernos de Historia de la Población 3-4 (2005): 65-122, 69.

9 Carlos Assadourian "La Conquista", en Argentina: de la Conquista a la Independencia, Carlos Assadourian, Guillermo Beato y José Carlos Chiaramonte, (Buenos Aires: Hyspamérica, 1972).

${ }^{10}$ Ricardo Freyre, Tucumán en la época de la conquista: medios de vida, precio de las cosas, (Buenos Aires: Consejo Nacional de Educación, 1915), 126.
} 
Y concluye diciendo que «la gente de esta provincia serán siete cientos hombres, vecinos, moradores y mercaderes y todos están ocupados en sus haziendas y granjerías» ${ }^{11}$.

Dentro de las principales familias de toda la región tucumana que alcanzaron considerables éxitos, tanto a nivel económico, como político y social hacia fines del quinientos y primera mitad del seiscientos, podemos mencionar a los Tejeda, los Cabrera, los Suarez de Figueroa, los Ávila y Zárate, los Fernández de Velasco, los Figueroa y Solís, los Guzmán, los Vera, los Medina y Villarroel, entre otros ${ }^{12}$. Merece la pena destacar a la familia de los Tejeda y a su fundador de la casa en Indias, don Tristán de Tejeda, héroe de la conquista del Tucumán, miembro del séquito fundacional de Cabrera en Córdoba, probablemente el hombre más rico de la región, y, en palabras del padre Diego de Torres, miembro de una de las más antiguas e ilustres casas de España, unida al linaje de los Guzmán, de quien procedieron los duques de Medinasidonia. Don Tristán comerciaba esclavos, vinos, textiles, mulas y vacas con destino a Chile, además ocupó cargos en el cabildo local y en 1591 fue nombrado teniente de gobernador de Córdoba ${ }^{13}$. No podemos afirmar fehacientemente las razones, pero ante la llegada de Ribera al gobierno, tanto don Tristán como sus descendientes, no ocuparon cargos en el cabildo, pero aún así no dejaron de participar en la esfera pública ya que los dos hijos de don Tristán, don Juan de Tejeda y Guzmán y doña Leonor de Tejeda y Miraval fundaron los conventos de las Teresas y las Catalinas respectivamente. La fundación de ambos conventos le otorgó a la familia Tejeda un inigualable prestigio social en toda la región ${ }^{14}$. Posteriormente, los Tejeda gozaron de un mayor reconocimiento durante el gobierno de Alonso de Vera y Zárate (1618-1627), cuando este gobernador designó a don Juan como teniente de gobernador y justicia mayor, agregando por primera vez el título de capitán de guerra y capitán de infantería ${ }^{15}$.

Por su parte, los Cabrera desde que llegaron a Córdoba tuvieron representación en el cabildo local demostrando un fuerte posicionamiento. Un ejemplo de ello fue

${ }^{11}$ Carta de Gobernadores, Alonso de Ribera, Archivo General de Indias (en adelante AGI), Audiencia de Charcas (en adelante Charcas), 1608, s. f.

12 Isidoro Rodríguez, Los gobernadores de Córdoba desde 1573 3, no. 8, (1916), https://revistas.unc.edu.ar/index.php/REUNC/article/view/5687/6580 (consultado el 20 de septiembre de 2017).

13 Archivo Histórico de la Provincia de Córdoba, Protocolos, volumen 21, documentos 387, 388, 490; volumen 27, documentos 609 y 636; volumen 23, documentos 956, 969 y 801; volumen 24, documentos 1076; y volumen 25, documento 1165; para sus vinculaciones políticas, ver Lazcano Colodrero, Cabildantes de Córdoba, (Córdoba, 1944), 75 y 154-189.

${ }^{14}$ Para profundizar sobre la importancia de los conventos y sus fundadores en la sociedad tucumana ver: Guillermo Nieva Ocampo, "Mujeres de clausura: Identidad social y recambio generacional entre las dominicas de Córdoba del Tucumán (1613-1750), Archivo Dominicano: Anuario no. 29, (2008): 263-306.

${ }^{15}$ Héctor Ramón Lobos, "Córdoba en la geopolítica y en la organización institucional del gobierno español (1623-1776)", en Historia de Córdoba. Una sociedad peculiar, (Córdoba: Ediciones del copista, 2009), t. II, 9-75. 
don Pedro Luis, electo alcalde ordinario de $1^{\circ}$ voto en 1596, 1600, 1605 y 1619, procurador en 1601 y 1609, y finalmente teniente de gobernador y justicia mayor en marzo de $1612^{16}$. Aquí importa subrayar que todos estos títulos, oficios y cargos, se otorgaban únicamente a los miembros de las familias más encumbradas, jugando un importante papel los lazos de lealtad entre estas familias y los gobernadores de turno ${ }^{17}$.

En suma, debemos decir que esta sociedad se articulaba a través de relaciones de poder que jugaban dentro del marco jurídico de la Monarquía Hispana. Estas relaciones abarcaban el orden moral (poder religioso), el poder económico y el poder político, repartido en distintos niveles de cargos, de funciones y de espacios. En cada uno de ellos actuaban elementos ordenadores como el honor, el prestigio, y la parentela. El honor derivaba de las acciones provenientes de la conquista, o sea del servicio real, o también era heredado por los hechos de los padres o abuelos ${ }^{18}$. Esta sociedad fue, asimismo, el resultado de una compleja trama de interacciones, conflictos y negociaciones entre diferentes actores, coaliciones e individuos ${ }^{19}, \mathrm{y}$, fueron estos actores locales y regionales los que configuraron el poder del territorio tucumano convirtiéndolo en un espacio político ${ }^{20}$.

\section{ALONSO DE RIBERA, GOBERNADOR DEL TUCUMÁN}

El oficio de gobernador en Indias, durante el siglo XVI y primera mitad del siglo XVII, era ocupado en su inmensa mayoría por militares o funcionarios con experiencia en el oficio. Al reunir las funciones de gobierno, justicia y guerra, los gobernadores acumulaban amplios poderes, pero encontraban diversas limitaciones que les impedían proceder a su arbitrio. Por un lado, las funciones de gobierno eran compartidas con el cabildo y los alcaldes, y por otro, también convergían sobre aquéllos varios organismos de control que se ponían en movimiento apenas se percibían excesos en su conducta: el virrey, la Audiencia y el Consejo de Indias. Asimismo, los obispos y otros eclesiásticos, en informes y memoriales, se ocupaban de la actuación de los gobernadores para controlar y reducir su poder efectivo ${ }^{21}$.

El caso de Don Alonso de Ribera nos ilustra el ejemplo de un militar que fue acumulando méritos en su carrera de armas y que se consagró en Indias. Este personaje

\footnotetext{
${ }^{16}$ Rodríguez, Los gobernadores, 458-460; Carranza, ed., "Genealogía de los Tejeda", Revista de Buenos Aires. Historia americana, literatura y derecho XII (1867): 28-62.

${ }^{17}$ Lobos, "Córdoba en la geopolítica", 25.

${ }^{18}$ Carlos García Belsunce, "La sociedad Hispano-criolla", en Nueva Historia de la Nación Argentina Segunda Parte: La Argentina de los siglos XVII y XVIII, (Buenos Aires: Editorial Planeta, 1999), 149-150.

${ }^{19}$ Moutoukias, Gobierno y Sociedad, 364.

${ }^{20}$ Barriera, Abrir puertas a la tierra, 32-34.

${ }^{21}$ Víctor Tau Anzoátegui, "La Monarquía. Poder central y Poderes locales”, en Nueva Historia de la Nación Argentina Segunda Parte: La Argentina de los siglos XVII y XVIII, (Buenos Aires: Editorial Planeta, 1999), 230.
} 
antes de ser gobernador, tuvo 24 años de servicio como capitán en las guerras de Flandes, iniciándose cuando probablemente tenía 20 años de edad en $1579^{22}$. En 1596 Ribera regresó a Flandes, luego de participar en la expedición a Francia junto a Alejandro Farnesio, y allí fue elevado al grado de sargento mayor por orden del archiduque Alberto. Luego se dirigió a la península a solicitar un mayor premio por todos sus servicios ${ }^{23}$.

En 1599, Felipe III le confirió el cargo de gobernador en Chile cuando contaba con casi 40 años de edad. En palabras de Barros Arana, nunca se había enviado a América un soldado que posea «gran experiencia en los negocios de guerra» más distinguidos y mejor comprobados. Según este autor, el Consejo de Indias propuso a Ribera para tal cargo por recomendación del conde de Fuentes, persona que estuvo al mando de la segunda expedición a Francia luego de la muerte de Farnesio y que fue testigo de las actividades de Ribera. Lo cierto es que las noticias que llegaban a la península sobre la situación chilena y el conflicto con los indios araucanos requerían del envío de alguien que posea la capacidad militar para poner fin al problema ${ }^{24}$.

Durante los años que permaneció Ribera en Chile emprendió numerosas campañas de pacificación indígena desde Concepción hacia el sur y fundó diversos fuertes militares para frenar el avance de sus enemigos. Sin embargo, en opinión de sus opositores, su plan de guerra y proyecto iba en constante fracaso y de hecho, esas eran las noticias enviadas a la corte. En esas circunstancias, Felipe III nombró como reemplazo de Ribera para el cargo de gobernador y capitán general de las provincias chilenas a don Alonso de Sotomayor, el 9 de enero de 1604. Ante la negación de este personaje para tomar dicho cargo, el virrey peruano Gaspar de Zúñiga y Acevedo nombró a don Alonso García Ramón. De acuerdo a estos nombramientos, Ribera debía pasar a desempeñar el puesto de gobernador del Tucumán, cuya plaza era el mejor acomodo que se había hallado para premiar sus anteriores servicios. A fines de octubre de 1605 Ribera emprendió el viaje hacia aquella gobernación junto a su esposa, criados, veintinueve soldados y once oficiales, capitanes, alféreces, amigos y allegados ${ }^{25}$.

22 Alonso de Ribera y Zambrano fue miembro de una familia de modesta fortuna y de buena alcurnia, nació alrededor de los años 1560 en la ciudad de Úbeda en Andalucía. Ver Diego Barros Arana, “Alonso de Ribera: principios de su gobierno (1601)", en Historia General de Chile, (Santiago de Chile: Editorial Universitaria, Centro de Investigaciones Diego Barros Arana, 1999 2a. ed.), t. III, 254, http://www.memoriachilena.cl/602/w3-article-7987.html, (consultado el 15 de julio de 2016).

${ }_{23}$ Barros Arana, "Alonso de Ribera: principios", 257. Sobre todas las actuaciones de Ribera en Flandes ver Vázquez Alonso, "Los sucesos de Flandes. Francia del tiempo de Alejandro Farnese", en Colección de documentos inéditos para la historia de España, (Madrid, 1879-1880), t. 72, 73 y 74. Sobre las expediciones del duque de Parma y la participación de Ribera en ellas, ver: Carlos Coloma, Las guerras de los Estados Bajos desde 1588, (Amberes, 1625), libro IV, VII y VIII.

${ }^{24}$ Sobre el desempeño de Ribera en la guerra contra el Arauco y la gestión del gobierno chileno, ver Informaciones: Alonso de Ribera, AGI, Audiencia de Chile (en adelante Chile), 40, N. 13, 1605, s. f. Además, está disponible la interpretación que realizó Barros Arana en Historia General de Chile, t. III.

${ }^{25}$ Relación de las cosas que del reino de Chile se debe dar entero aviso a V.M. por vuestro gobernador Alonso García Ramón, AGI, Chile, 1607, s. f. 
Debemos tener en cuenta que durante los 30 años previos a la llegada del nuevo gobernador, el Tucumán se constituyó en un auténtico brazo político del proyecto toledano, instrumentalizados por Jerónimo Luis de Cabrera, Gonzalo de Abreu y Hernando de Lerma. Los tres formaron parte del entorno inmediato del Virrey Toledo y respondieron a su tutela ${ }^{26}$. De hecho, por disposición de Toledo, Abreu debió implementar una serie de reformas en 1576 sobre el sistema de tributación anclado en el régimen de encomienda. Desde 1570, el virrey Toledo intentó imponer sobre toda la región andina la monetización del tributo. Sin embargo, en la gobernación del Tucumán, el poder local crecía cada vez más por lo que el régimen de encomienda y tributación presentaban características específicas, dentro de las cuales, como mencionamos anteriormente, se destacó la continuidad del servicio personal y las encomiendas privadas ${ }^{27}$. En consecuencia, el gobernador Barrasa y Cárdenas informó en una carta al rey en 1604 que el servicio personal persistía y denunció las actitudes agraviantes que los encomenderos tenían hacia sus poblados indígenas ${ }^{28}$. No obstante, según Castro Olañeta este gobernador proclamó la necesidad del cumplimiento de las ordenanzas dictadas por Abreu, pero nunca tomó las medidas concretas para ponerlas en práctica de manera efectiva ${ }^{29}$.

Dentro de este contexto debemos ubicar la llegada el 20 de enero de 1606 de Alonso de Ribera quien inmediatamente envió una carta al Rey informando sobre la situación en la que se encontraba la ciudad de Córdoba ${ }^{30}$. Luego dirigió su viaje a Santiago del Estero, sede de gobierno, y procedió de la misma forma. Una de las principales medidas aplicadas por el gobernador fue la creación de una nueva institución: la de «Teniente de naturales» para controlar los malos tratos hacia los indios. Este agente era el equivalente del corregidor implementado en el Perú por el virrey Toledo años anteriores. Por otra parte en el Tucumán, Ribera intentó, al igual que en Chile, implementar un ejército Regular para controlar la resistencia del Valle Calchaquí, poner en servicio a los indios encomendados y «descubrir el chaco». No obstante, este último pedido fue rechazado por el rey, ordenando que la pacificación se realizara por medio de religiosos ${ }^{31}$.

${ }^{26}$ Darío Barriera, "Un rostro local de la Monarquía Hispánica: justicia y equipamiento político del territorio al sureste de Charcas, ss. XVI y XVII", Colonial Latin American Historical Review 15, no. 4 (2006): 377-418, 391.

${ }^{27}$ Isabel Castro Olañeta, "Vuestra Magestad se sirva de ordenar al Governador, que no apriete en las ordenanzas del Visitador. Gobierno colonial y poder local en la Gobernación del Tucumán (16031619)", Bibliographica Americana no. 9 (2013), 23-48, 28.

${ }^{28}$ Carta de Gobernadores, Alonso de Barrasa y Cárdenas, AGI, Charcas, 26, R. 7, N. 32, 1603.

${ }^{29}$ Castro Olañeta "Vuestra Magestad", 31.

${ }^{30}$ Carta de Gobernadores, Alonso de Ribera, AGI, Charcas, 26, R. 8, N. 39, 1607. Las cartas de los gobernadores suponen una documentación sumamente importante para el estudio de la historia política colonial, ya que en ellas puede leerse la agenda de gobierno que proponía cada gobernante.

${ }^{31}$ Leticia Carminagni, "Política colonial y sociedades indígenas en la Gobernación del Tucumán. El gobernador Alonso de Ribera, los Tenientes de naturales y la élite encomendera durante la vigencia de las Ordenanzas de Abreu", Sintesis, artículos basados en tesinas de grado, no. 4 (2013), 3, https://revistas.unc.edu.ar/index.php/sintesis/article/view/12228 (Consultado el 5 de mayo de 2016). 
Otra de las actividades que realizó el gobernador fue fundar una nueva ciudad: San Juan Bautista de la Ribera de Londres, en el Valle de Catamarca. Asimismo, se interesó por el problema de Talavera de Esteco, creyendo que la mejor solución era unir sus habitantes a los de Madrid de las Juntas y erigir una nueva ciudad. Una vez obtenida la autorización necesaria, procedió a fundar Nuestra Señora de Talavera de Madrid $^{32}$. Hay que decir que cuando el gobernador estuvo en Chile también tuvo esta iniciativa fundacional, y es que, a pesar de que ya estaba enterado de su traslado al gobierno tucumano, tenía resuelto hacer dos nuevas fundaciones, una en el valle central y la otra en los campos de la costa del rio Paicavín

De este modo, la campaña que emprendió la Corona en aquellos años era la de un aumento de la autoridad en aquellas regiones alejadas, es decir la reducción del poder de los vecinos encomenderos, y la mayor percepción de los recursos materiales y monetarios. Ribera fue quien instrumentalizó en el Tucumán el proyecto de la nueva orientación política de Felipe III que se expresaba en las reales cédulas de 1601, 1605 y 1609. En ellas se prohibía el servicio personal y recordaba la condición de hombres libres de los indígenas y ordenaba a la Audiencia de Charcas la visita a las gobernaciones del Tucumán y del Río de la Plata con el fin de erradicar la encomienda de servicio, tasar el tributo y desagraviar a los indígenas ${ }^{34}$. Poner en marcha este plan fue el motivo que lo llevó a su enfrentamiento con el obispo y las élites locales.

\section{HERNANDO DE TREJO Y SANABRIA, OBISPO DEL TUCUMÁN}

Paralelamente, en las primeras décadas del siglo XVII sobresalió otra figura destacable, el Obispo don Hernando de Trejo y Sanabria, fraile franciscano y criollo, interesado en mejorar la organización del ministerio sacerdotal y la perfección de las instituciones religiosas. Presentado por Felipe II el 9 de noviembre de 1592, aceptó el 3 de enero de 1594 la real merced y arribó al obispado en marzo de $1597^{35}$. Los obispos han tenido una importancia central en la historia, tanto eclesiástica como política, de la Monarquía Hispana, ya que fueron dirigentes en materia religiosa y "civil",

\footnotetext{
32 Sierra, "La Gobernación”, 67-68.

33 Barros Arana, "Alonso de Ribera: principios", 324.

34 Archivo Histórico Nacional, Colección Documentos de Indias, Libro copiador de Reales Cédulas sobre Indias, Diversos-Colecciones, 30, N. 12, 1620.

${ }^{35}$ Cayetano Bruno, Historia de la Iglesia en Argentina, V. I, (Buenos Aires: Editorial Don Bosco, 1968), 350-490. Liqueno en 1916 afirmó que Trejo nació en San Francisco, en la costa del Brasil, población fundada por su padre, y despoblada un año después, trasladándose sus fundadores a la ciudad de Asunción. El obispo era hijo del adelantado Hernán de Trejo, "capitán y Cavallero", natural de Trujillo en Extremadura, y de María de Sanabria, también madre de quien luego fue el gobernador del Río de la Plata, Hernando Arias de Saavedra. Ver Enrique Martínez Paz, El nacimiento del Obispo Trejo y Sanabria. Fundador de la Universidad, (Córdoba: Imprenta de la Universidad de Córdoba, 1946), 24.
} 
compartieron muchos rasgos de los funcionarios seculares y reunían en su persona la figura tradicional del patronus y el papel bíblico de juez ${ }^{36}$.

Trejo y Sanabria pasó su niñez en Asunción, donde su familia estaba radicada; en referencia a su vida durante sus primeros años sólo se conserva el testamento del padre del obispo, publicado por Liqueno. Respecto a su juventud, la transcurrió en el Perú, centro de instrucción donde acudían los jóvenes nobles de aquella época. Allí le fueron conferidas las órdenes sagradas entre los religiosos de San Francisco y pronto alcanzó la dignidad de Provincial de su Orden en 1588. En 1592 le sorprendió la elección de su persona para ocupar el cargo de obispo del Tucumán ${ }^{37}$.

A la par de la administración en manos de Trejo, la diócesis contaba con un Cabildo Catedralicio para ayudar en los asuntos eclesiásticos. Asimismo, aquel estaba presidido por el mismo obispo y sólo contaba con un deán, un arcediano, un tesorero, el cantor y tan sólo dos o tres canónigos, debido a la pobreza de las rentas anuales de los diezmos, que al ser tan bajos no permitía el mantenimiento de un mayor número de oficios divinos ${ }^{38}$. El obispo convocó a tres Sínodos diocesanos realizados en Santiago del Estero en 1597, 1606 y 1607, estos debían aplicar las medidas establecidas en el Concilio Limense, y éste, a su vez, acataba lo estipulado por el Concilio de Trento. El objetivo era fijar diversas normas dirigidas a los canónigos de la catedral y a los curas doctrineros. Como resultado de ello, se promulgaron varias ordenanzas sobre el trato y conversión de los indios, como así también sobre las buenas costumbres de la población en general ${ }^{39}$. Las medidas que se intentaron poner en marcha - muchas sin éxito - también respondieron al programa monárquico generalizado que pretendía organizar, administrar y disciplinar cada detalle en materia religiosa. A nivel local el objetivo era homogeneizar el culto divino, el modo de administrar la diócesis y la formación de los sacerdotes, aspectos desiguales que variaban de acorde a cada ciudad de la región.

\footnotetext{
${ }^{36}$ Una obra que caracteriza a los obispos como funcionarios de la corona: Javier González Echenique, "Los obispos de Indias como funcionarios de la Corona", en Revista chilena de Historia del Derecho no. 6, (1970), 143-151. Los Austrias, desde su ejercicio del Patronato, cuidaron la selección de los obispos, es decir, exigían candidatos virtuosos, cultos, competentes, de acuerdo con su entorno familiar y su clientela; la carrera episcopal fue un auténtico cursus honorum en el que se ocupaban cargos cada vez mas importantes de acorde a los méritos que éstos realizaban para con la Corona. Véase Beatriz Comella Gutiérrez, "Los nombramientos episcopales para la corona de Castilla bajo Felipe III, según el Archivo Histórico Nacional: una aproximación”, Hispania Sacra no 122, (2008): 704-733, 706, http://hispaniasacra.revistas.csic.es/index.php/hispaniasacra/article/view/74/73 (Consultado el 7 de diciembre de 2016).

${ }^{37}$ Martínez Paz, El nacimiento del obispo, 32.

${ }^{38}$ Santiago Barbero, Estela Astrada y Julieta Consigli, "Relación Ad Limina del obispo Trejo", en Relaciones Ad Limina de los obispos de la Diócesis del Tucumán (s. XVII al XIX), (Córdoba-Argentina: Prosopis Editora, 1995), 9.

${ }^{39}$ Constituciones y declaraciones aprobadas en el primer Sínodo que hizo celebrar el obispo de Tucumán, don fray Fernando de Trejo y Sanabria en 1597, AGI, Charcas, 137, 1597.
} 


\section{EL PROYECTO DE RIBERA Y SU ENFRENTAMIENTO CON TREJO}

En una carta del 8 de abril de 1607, el obispo comunicó al rey sobre la «puntualidad» de Ribera en las cosas de su cargo y el celo que demostraba en el «servicio de Dios y del monarca», como probaban sus esfuerzos por asegurar la libertad y el buen trato de los indios. No obstante, su estima por Ribera no duró mucho tiempo, ya que luego destacó que el Tucumán gozaba de una «paz» que fue interrumpida ante la llegada del gobernador y «todo lo ganado con esfuerzo, se había perdido». De este modo, no fue casual que el eclesiástico aconseje al monarca que vuelva a colocar a Ribera en el gobierno chileno ${ }^{40}$.

De hecho, un desencadenante que derivó en las disputas entre estos dos personajes a mediados de 1608 tuvo que ver con la orden del teniente Gaspar Doncel, quien mandó a ahorcar cinco indios y dos indias de San Juan Bautista de la Rivera ${ }^{41}$. Este hecho produjo indignación en Trejo y fue considerado como un acto irresponsable de Ribera por no tomar las medidas correspondientes contra su Teniente natural. A su vez, en la «Información y probanza», que compuso el tesorero y principal aliado del obispo Francisco Salcedo en 1609, expresaba: «desde que entró en esta provincia el dicho Gobernador siempre ha menospreciado con gran desacato las cosas de la Iglesia y prelados della y sus ministros». También el padre Juan Serrano, uno de los testigos, expresó que Ribera no había tenido un comportamiento adecuado en el Sínodo de 1607 y que merecía la excomunión por no aplicarle una pena a su teniente Gaspar Doncel ${ }^{42}$.

Debido a estas declaraciones, Trejo debía excomulgar a don Alonso según la ley canónica que prescribe el fuero Ratione Delecti. No obstante, el obispo, y gracias a su «espíritu conciliador», intentó solucionar esta disputa enviando mensajeros a Chile y a la Real Audiencia de los Reyes para recabar información sobre los procederes de Ribera en aquel reino. Por su parte, este dirigió su apelación a la Audiencia de Charcas, pero Trejo al fin debió comunicar su excomunión. No conforme con ello, el gobernador, aplicando otra estrategia, envió una carta al rey, remarcando todos los servicios que había realizado a la corona, nombrando las guerras de Flandes, Chile y su labor en el Tucumán, para que no se apliquen sobre él las condenas que pretendía el obispo. En ella acusaba a Trejo y Salcedo de ser «tan poderosos [que] se an llebado a casi todo el pueblo» como «contrarios» a él, cuando su máxima pretensión era defender la «jurisdiçion real» ${ }^{43}$.

Una vez que Ribera acusó a Trejo y al comisario del Santo Oficio Salcedo como sus principales contrarios y conspiradores, reaccionó de la misma manera que el

\footnotetext{
40 Sierra, "La Gobernación”, 70-71.

${ }^{41}$ Bruno, Historia de la Iglesia, 383.

42 Ibídem, 380.

${ }^{43}$ Carta de Gobernadores, Alonso de Ribera, AGI, Charcas, 26, R. 8, N. 62, 1611.
} 
obispo y ordenó al vicario parroquial que realice una información contra él y luego lo excomulgue. El vicario, acosado por el gobernador, accedió a su pedido. Ante esta situación tuvo que intervenir el clérigo Juan Darío, rector del colegio de la Compañía de Jesús de Santiago del Estero para poner fin al conflicto y no llegar a la excomunión del obispo. Luego de estas largas contrariedades, que no beneficiaba a ninguna de las partes, Ribera pidió perdón general por los disgustos ocasionados y suplicó que le restituyeran su gracia. La significación del episodio es evidente, muestra hasta qué punto el episcopado constituía una fuerza de contención de los desmanes del poder civil y viceversa.

La actitud del padre Juan Darío ante este conflicto representa el rol intermediario que muchos de los miembros de la Compañía de Jesús cumplieron, ya que eran aliados tanto de Trejo y Salcedo, como de Ribera. La lucha contra la encomienda de servicio también fue sostenida por los jesuitas en la gobernación. En el caso del gobernador, este se había casado con doña Inés de Córdoba y Aguilera, quien le sumó poderosos protectores jesuitas desde su residencia en Chile. Su esposa era hermana de un padre jesuita ${ }^{44}$, y en esa época la Compañía de Jesús comenzaba a tomar una gran influencia en todos los negocios políticos y administrativos en todos los reinos hispánicos ${ }^{45}$. De hecho, el virrey Montesclaros en una carta escrita al rey en el año 1610 informó:

Alonso de Ribera está casado con una hermana de un padre de la Compañía de Jesús, y con este medio ha sabido ganar la voluntad a esta religión, calidad que a solas basta en la Indias para encubrir cualquier defecto en un Gobernador, y sin la cual las mejores acciones se deducen, por más que ellas hablen, si estos padres callan ${ }^{46}$.

En cuanto al obispo y su buena relación con los jesuitas quedó documentada con las donaciones que realizó años posteriores para la fundación de algunas casas y seminarios ${ }^{47}$. De hecho, el padre Juan de Viana expresó que:

${ }^{44}$ Inés de Córdoba y Aguilera era hija de Inés de Aguilera Villavicencio y del capitán Pedro Fernández de Córdoba. Ribera se casó con doña Inés en Concepción en el año 1603. Una breve descripción de las negociaciones para este matrimonio se encuentra en la carta enviada por Ribera a Felipe III, Concepción 29 de abril de 1603 y citada por Barros Arana, "Gobierno de Alonso de Ribera", 265.

${ }^{45}$ Sobre la creación de la provincia jesuita del Tucumán, Paraguay y Buenos Aires, véase, Aliocha Maldavsky, Vocaciones inciertas. Misión y misioneros en la provincia jesuita del Perú en los siglos XVI y XVII, (Sevilla: CSIC, 2012), 100-124. Sobre la relación de los jesuitas del Tucumán con las élites locales, véase Guillermo Nieva Ocampo: "Cimentar las identidades locales: los jesuitas y las elites sociales del Tucumán (1600-1650)”, en Jesuitas: religión, política y educación (ss. XVI-XVIII), José Martínez Millán y Esther Jiménez Pablo, coords., (Universidad Pontificia Comillas/Polifemo, 2012), 1399 - 1418.

${ }^{46}$ Carta del marqués de Montesclaros, virrey del Perú, a Felipe III, escrita toda ella de su propia mano, en 21 de noviembre de 1610, reproducida por Barros Arana, "El Gobierno de don Alonso de Ribera", 270.

47 AGI, Charcas, 26. 
El Señor Obispo, en presencia y ausencia, en palabras y obras, muestra la mucha estima y amor que tiene a la Compañía, de ver la puntualidad y cuidado que hay de nuestra parte en ayudar a las almas. Ha dicho muchas veces que si la Compañía le faltase, luego dejaría su obispado ${ }^{48}$.

Por su parte, don Francisco Salcedo fue otro importante donante de la Compañía, otorgándoles uuna estancia con muchos ganados maiores y menores y negros y casas y chacras y otras cosas que montan de rrenta al dicho collegio más de cuatro mil pesos» en la jurisdicción de la cuidad de Talavera de Madrid ${ }^{49}$.

Es innegable que los padres de la reciente instalada provincia jesuítica secundaban las medidas de la Corona de mermar el poder de los encomenderos, pero esta posición les restó el apoyo de los vecinos, viéndose obligados a abandonar algunos de sus colegios y también a comprar fincas para sostener sus emprendimientos que no se cubrían completamente con las donaciones mencionadas ${ }^{50}$. Por su parte, la posición de Trejo respecto a esta problemática es ambigua, ya que, si bien en muchas ocasiones se manifestó en contra de los malos tratos hacia los indígenas, siempre puso trabas a la aplicación de las ordenanzas de Abreu que Ribera quería efectivizar.

Dicho esto, el trasfondo del problema entre el obispo y el gobernador devenía del descontento y poco prestigio que tenía Ribera ante los vecinos encomenderos, consecuencia además de su inminente preocupación por la situación que atravesaba la gobernación. En una lista de reclamos que envió a la Audiencia de Charcas remarcaba los comportamientos inadecuados por parte de los vecinos ya que «por sus intereses derogan las ordenanças de su magestad y descomulgan a quien las executa» ${ }^{51}$. Un dato importante que nos deja este fragmento - además de las amenazas vistas anteriormente entre Trejo y Ribera - es que la excomunión era utilizada como una herramienta política, para mermar o frenar las medidas poco favorables a los sectores de mayor poder. En este sentido, al privar a alguien de los sacramentos y demás beneficios espirituales, suponía una marginación traumática no sólo religiosa, sino también social ${ }^{52}$. A propósito de ello, Trejo en las Constituciones y declaraciones aprobadas en el tercer Sínodo de septiembre de 1607 instó a que curas y vicarios no promulguen excomuniones para «cobranza de poca cantidad, sino que primero yntenten otros

\footnotetext{
${ }^{48}$ Carta Anua del P. Lima, 1-5-1607, ARSI, Peruana Litterae Annuae, II, 13, f. 24.

49 Información de servicios hechos por don Francisco Salcedo, Canónigo de la Catedral de los Charcas, en la provincia de Tucumán, siendo uno de los principales haber servido más de treinta años en el Tucumán como tesorero y canónigo, y haber obsequiado a los religiosos de la Compañía de Jesús con un Colegio en San Miguel y los bienes necesarios para sostenerlo, La Plata, 1616, reproducido por Roberto Levillier, Papeles eclesiásticos del Tucumán. Documentos originales del Archivo de Indias, (Madrid, Imprenta de Juan Pueyo, 1926), vol. I, 114.

${ }^{50}$ Nieva Ocampo "Cimentar las identidades locales", 1404.

${ }^{51}$ Carta de Gobernadores, Alonso de Ribera, AGI, Charcas, 26, R. 8, N. 54, 1608.

52 Enrique Martínez Ruiz, dir., y AA.VV., Diccionario de Historia Moderna de España, La Iglesia, (Madrid: ISTMO, 1998), t. I, 131.
} 
medios más suaves y quando lo ayan de poner sea guardando el orden judicial» ${ }^{53}$. Quizás esta situación explica que haya perdonado a Ribera restituyéndole su gracia y honor en el año 1611.

Por las diversas situaciones mencionadas es que Ribera debió solventar su poder sobre la mayor cantidad de alianzas personales que eran esenciales para el desarrollo de su gestión, y en definitiva, para la de cualquier agente político en el Antiguo Régimen. En este sentido, a pesar de manifestarse en contra de esta práctica, Ribera nombró a Luis de Abreu de Albornoz, personaje principal de la ciudad de Córdoba, participante de la fundación, encomendero y anterior tesorero de la Real Hacienda, alguacil mayor, regidor y procurador general, y «teniendo en cuenta su prestigio, el gobernador en septiembre de 1606 lo designó lugarteniente, justicia mayor y capitán de guerra hasta fines de 1608». Otro ejemplo fue Luis de Azpetetia, licenciado y abogado de la Real Audiencia de Charcas, nombrado por Ribera como teniente de gobernador en la Ciudad de todos los Santos de la Nueva Rioja, lugar donde don Luis poseía sus intereses ${ }^{54}$. Por aquellos tiempos, el prestigio lugareño solo podía ser compensado con importantes funciones de gobierno, civil o eclesiástico, por lo tanto el gobernador debió otorgarles a estos miembros de la elite encomendera cargos en los Cabildos para cumplir principalmente con dos objetivos, por un lado, mantener la cohesión política en una gobernación territorialmente extensa, y por el otro, evitar el descontento de estos personajes al verse menospreciados si se les negaba la participación política. De este modo el gobernador sí logró reforzar su poder a través de estos nombramientos, y sobre todo con el de los tenientes de naturales y gobernadores que eran allegados a él. No debemos dejar de mencionar que algunos de sus tenientes no fueron lugareños ya que provenían de los contingentes de «refuerzos militares» que se dirigían a Chile, previo paso por Tucumán, y de esa forma «mantenían una desvinculación con la élite local y los círculos sociales o económicos regionales que resulta coherente a la posición del gobernador respecto a que dichos funcionarios no debían ser 'amigos' de los encomenderos»"

Hasta finalizar el valimiento de Lerma en 1618, la política general de la Corona y su equipo de gobierno se caracterizó por tener una ambición «pacificadora», no de expansión - como sí lo fue durante el reinado de Felipe II - es decir, se trató de

\footnotetext{
53 Constituciones y declaraciones aprobadas en el tercer Sínodo celebrado por mandado de don Fray Fernando de Trejo y Sanabria, obispo de las provincias de Tucumán, Santiago del Estero, septiembre de 1607, en Levillier, Papeles eclesiásticos, 74.

${ }^{54}$ Colodrero, Los cabildantes, 7.

${ }_{55}$ Carmignani, "Política colonial", 15. El mismo Felipe II en 1569 ordenó que quien ocupe el cargo de teniente de gobernador no debiera ser vecino de la ciudad, o ser pariente de alguno, ni residir en ella. De esta forma se pretendía garantizar la actuación imparcial por parte de aquellos agentes que muchas veces generaban una superposición del servicio real y de los intereses locales. Ver Darío Barriera, "Resistir al teniente con la letra del rey: la conflictiva relación del Cabildo de Santa Fe con la Gobernación del Río de la Plata durante los años 1620", en Homogeneidad, diferencia y exclusión en América, Encuentro debate América Latina, Gabriela Dalla Corte y otros, coords., (Barcelona: Publicacions i edicions de la Universitat de Barcelona, 2006), 65-71.
} 
una política de «conservación de la Monarquía», pero a la vez, con un impulso reformista del «sistema administrativo» americano. Felipe III y Lerma pretendían un fortalecimiento institucional, económico, social y cultural. El valido instrumentalizó estos deseos a través de sus conexiones indianas, abocados a cumplir dichos objetivos, en una Monarquía que necesitaba recursos y que estaba dispuesta a negociar con sus reinos $^{56}$. Quien encabezó estas pretensiones sobre América fue el VII conde de Lemos, sobrino y yerno de Lerma, cuando fue nombrado por el duque Presidente del Consejo de Indias (1603-1609). Es decir, en esa línea se enmarca el proyecto de recabar información americana fidedigna, como paso previo para administrar los reinos indianos de acuerdo a los planes reales ${ }^{57}$. De hecho, en 1604 el Presidente Lemos emitió una Real Cédula que dispuso la realización de un cuestionario para posteriormente confeccionar unas relaciones que diera a conocer la verdadera situación de aquellos territorios ${ }^{58}$. En esas condiciones Ribera llevó a cabo un relevamiento y conocimiento de la composición social en número y origen de los habitantes de la Gobernación tucumana. Para ello elaboró diversos Informes que hasta el momento no tenía antecedentes en dicho dominio y envió en 1608 una aproximación y relación incluyendo un censo de vecinos, residentes, moradores y clérigos respondiendo al cuestionario de la corona. Anteriormente, en el año 1607 contabilizó las Iglesias, conventos y ermitas, distinguiendo ciudades y órdenes religiosas. En 1610 fue el turno de un censo de «portugueses y demás extranjeros», esperando la orden real de expulsar a los que no tengan condición de vecino ${ }^{59}$. En el plano económico, la idea de Ribera fue la de generar una «conexión regional», abriendo el puerto de Buenos Aires para llegar a destinos como Brasil, Angola e islas vecinas, para comerciar trigo, cecina, sebo y comprar esclavos, aceite, hierro, etc. ${ }^{60}$. Esta idea respondía a su vez a la intención del presidente del Consejo de Indias que quería «abrir vías al comercio y fomentar el progreso» ${ }^{61}$. Independientemente del éxito o no, no podemos negar que la acción de Ribera significó la proyección del programa lemista en esta gobernación.

\footnotetext{
56 Amorina Villarreal Brasca, "Gestión política indiana en tiempos de Felipe III: A propósito del patronazgo del duque de Lerma (1598-1618)”, Naveg@mérica. Revista electrónica editada por La Asociación Española de Americanistas, no. 11, (2013): 1-15, 5, http://revistas.um.es/navegamerica/article/view/184281/153491 (consultado el 4 de marzo de 2015).

${ }^{57}$ Villarreal Brasca, Ibídem.

58 Ibídem, 7.

${ }^{59}$ Carmignani, "Política colonial”, 10-11.

${ }^{60}$ Ibídem.

${ }^{61}$ El conde instauró políticas dirigidas a la mejora de las gentes bajo su jurisdicción, abriendo vías al comercio y fomentando el progreso; elaboró un Memorial solicitando del rey la libertad de los indios, y fundamentando meticulosamente las razones que le llevaban a elevar tal petición. El 26 de mayo de 1609, Felipe III promulgó la Real Cédula que promovió la medida solicitada. Ver Isabel Enciso AlonsoMuñumer, Linaje, Poder y Cultura. El virreinato de Nápoles a comienzos del XVII. Pedro Fernández de Castro, VII Conde de Lemos, (Tesis Doctoral, Universidad Complutense de Madrid, 2002), 215, http://biblioteca.ucm.es/tesis/ghi/ucm-t25961.pdf, (Consultado el 4 de enero de 2017).
} 
A modo de cierre, podemos afirmar que la puesta en marcha del proyecto del conde en el Tucumán por parte de don Alonso le generaron las disputas con el obispo y la mayor parte de la élite local. El gobernador constantemente acusó al obispo de justificar el servicio personal y de beneficiarse de él a pesar de que este lo negara ${ }^{62}$. A fin de cuentas, el servicio personal fortalecía el poder de la élite encomendera a la cual le disgustaba el preceder del gobernador y no del obispo. Finalmente, tras estos enfrentamientos, Ribera recibió una Real Cédula que lo nombraba gobernador de Chile - nuevamente - y presidente de la Real Audiencia en 1611, lo que suponía un ascenso en su carrera ${ }^{63}$, ya que su mayor interés estaba puesto en aquel reino. Asimismo, no podemos negar que el alejamiento de Ribera del Tucumán significó por una parte, el triunfo de los encomenderos que no querían perder sus privilegios, y por otra, el fracaso del proyecto del gobernador al no liberalizar el puerto de Buenos Aires, no implementar el ejército regular en el Valle Calchaquír ${ }^{64}$ y no aplicar las Ordenanzas de Abreu. Por su parte, el obispo Trejo pidió al rey la retribución por sus servicios, es decir, la promoción hacia el arzobispado de Charcas, pero no consiguió una respuesta favorable y murió en el Tucumán en 1614.

\section{BIBLIOGRAFÍA}

Aguirre Salvador, Carrera, linaje y patronazgo, Clérigos y juristas en Nueva España, Chile y Perú, (México: Plaza y Valdés, 2004).

Arrigo Amadori, Negociando la obediencia. Gestión y reforma de los virreinatos americanos en tiempos del conde-duque de Olivares (1621-1643), (Madrid: CSIC-Universidad de Sevilla, 2013).

Alfredo Alvar Ezquerra, El duque de Lerma. Corrupción y desmoralización en la España del siglo XVII, (Madrid: La Esfera de los Libros, 2010).

Eduardo Arancivia Torres, E., Corte de virreyes: el entorno del poder en el Perú en el siglo XVII, (Lima: Fondo Editorial PUCP, 2006).

Francesco Benigno, La sombra del rey. Validos y lucha política en la España del siglo XVII, (Madrid: Alianza, 1994).

\footnotetext{
${ }^{62}$ Carlos Crouzeilles, Religiosos y sociedad colonial. Los religiosos, su ingreso al Tucumán y su incidencia politica en el sistema de explotación económico sobre la sociedad indígena (Tucumán, 1535-1615) (Trabajo Final Licenciatura en Historia, Universidad Nacional de Córdoba-Argentina 2007).

${ }^{63}$ Sierra, La Gobernación, 73.

${ }^{64}$ Carmignani, "Política Colonial", 18.
} 
Pedro Borges, "Los artífices de la evangelización", en Borges, La historia de la Iglesia en Hispanoamérica y Filipinas, vol. I: Aspectos generales, (Madrid: Biblioteca de Autores cristianos), 1992.

Cayetano Bruno, Historia de la Iglesia en Argentina, V. I, (Buenos Aires: Editorial Don Bosco, 1968).

Isabel Castro Olañeta, "Vuestra Magestad se sirva de ordenar al Governador, que no apriete en las Ordenanzas del visitador. El gobierno colonial y poder local en la Gobernación del Tucumán (1603-1619)", Bibliographica Americana, Revista Interdisciplinaria de Estudios Coloniales, no 9, (Biblioteca Nacional, 2013).

Leticia Carminagni, "Política colonial y sociedades indígenas en la Gobernación del Tucumán. El gobernador Alonso de Ribera, los Tenientes de naturales y la élite encomendera durante la vigencia de las Ordenanzas de Abreu", Sintesis, articulos basados en tesinas de grado, no 4, (2013).

Comella Gutiérrez, "Los nombramientos episcopales para la corona de Castilla bajo Felipe III, según el Archivo Histórico Nacional: una aproximación”, Hispania $\begin{array}{llll}\text { Sacra, } & \mathrm{n}^{\circ} \quad \text { (22, } & \text { (jul-dic 2008), }\end{array}$ https://doi.org/10.3989/hs.2008.v60.i122.74, Consultado el 4 de junio de 2013.

Carlos Crouzeilles, Religiosos y sociedad colonial. Los religiosos, su ingreso al Tucumán y su incidencia política en el sistema de explotación económico sobre la sociedad indígena (Tucumán, 1535-1615). (Trabajo Final Licenciatura en Historia. Escuela de Historia, Córdoba: FFyH-UNC, 2007).

Alicia Esteban Estríngana, El servicio: paradigma de relación política en los siglos XVI y XVII, (Madrid: Sílex ediciones, 2012).

Antonio Feros, El duque de Lerma. Realeza y privanza en la España de Felipe III, (Madrid: Marcial Pons, 2002) [Cambridge, 2000].

Carlos García Belsunce, "La sociedad Hispano-criolla", en Nueva Historia de la Nación Argentina Segunda Parte: La Argentina de los siglos XVII y XVIII, Academia Nacional de la Historia (Buenos Aires: Editorial Planeta, 1999).

Bernardo García García, Los validos, Madrid, (Madrid: Akal, 2006).

García y García, "La organización territorial de la Iglesia", en Pedro Borges, La bistoria de la Iglesia en Hispanoamérica y Filipinas, vol. I: Aspectos generales, (Madrid: Biblioteca de Autores cristianos, 1992). 
Gómez Rivero, R., "Lerma y el control de los cargos", en Los validos, Coords. Suárez Fernández \& Escudero López (2004), 81-120.

González Echenique, "Los obispos de Indias como funcionarios de la Corona”, Revista chilena de Historia del Derecho, No. 6, (1970, 143-151).

Ricardo Levene, Las Indias no eran colonias, (Bs. As.: Espasa-Calpe, 1951).

Mantecón Movellán, T. A. \& Truchuelo García, S., La(s) frontera(s) exteriores e interiores de la Monarquía Hispánica: perspectivas historiográficas, Historia Crítica, No 59, (Colombia: Universidad de los Andes-Facultad de Cs. Sociales, Departamento de Historia, ene-mar 2016). Dx.DOI.Org/10.7440/hIstcrIt59.2016.02, Consultado el 15 de febrero de 2017.

Ana María Martínez de Sánchez, "Influencias peninsulares en la iglesia indiana. El obispado del Tucumán", en Dos mil años de evangelización: los grandes ciclos evangelizadores, (Pamplona: Universidad de Navarra, 2001).

José Martínez Millán, “Cambios en la corte y en la forma de gobierno. Introducción”, en La Monarquia de Felipe III: La Corte, vol. I, dirs. J. Martínez Millán, \& M. A. Visceglia (Madrid: Fundación MAPFRE - Instituto de Cultura, 2008).

Oscar Mazín, "Representaciones del poder episcopal en Nueva España (siglos XVII y primera mitad del XVIII)", en Las representaciones del poder en las sociedades hispánicas, (México: El Colegio de México, Centro de Estudios Históricos, 2012).

Guillermo Nieva Ocampo, G., "Cimentar las identidades locales: Los Jesuitas y las élites sociales del Tucumán (1600-1650)", en Los Jesuitas. Religión, política y educación (siglos XVI-XVIII), Tomo III, coords. J. Martínez Millán, H. P. Llorente \& E. Jiménez Pablo, (Madrid: Universidad Comillas, 2012).

Manuel Rivero Rodríguez, "Virreyes y Virreinatos en la Historia", Introducción, en La edad de oro de los virreyes. El virreinato en la Monarquía Hispánica durante los siglos XVI y XVII, (Madrid: Ediciones Akal, S. A., 2011).

Manuel Rivero Rodríguez, "La reconstrucción de la Monarquía Hispánica: la nueva relación con los reinos (1648-1680)", Revista Escuela de Historia, vol. 12, no. 1, (2013). 
Vicente Sierra, "La Gobernación del Tucumán desde 1600 a 1619”, en Historia de la Argentina. Bajo el Reinado de Felipe III. Libro I., (Bs. As.: Editorial Científica Argentina, 1957).

Víctor Tau Anzoátegui, "La Monarquía. Poder central y Poderes locales", en Nueva Historia de la Nación Argentina Segunda Parte: La Argentina de los siglos XVII y XVIII, Academia Nacional de la Historia, (Buenos Aires: Editorial Planeta, 1999).

Susana Truchuelo, "Servicio y reciprocidad en la Monarquía Hispánica: prácticas de gobierno entre la corte y los territorios en el Antiguo Régimen", en El principe, la corte y sus reinos. Agentes y Prácticas de gobierno en el mundo hispano (ss. XIV al XVIII), coords. G. Nieva Ocampo, Rubén González Cuerva \& Andrea Navarro (San Miguel de Tucumán: Universidad Nacional de Tucumán, Facultad de Filosofía y Letras, 2016).

Oscar José Trujillo, "Los gobernadores de Bs As. A mediados del S. XVII: mediación y conflicto en los confines de la Monarquía Hispánica", en História, histórias, vol. 2, no 3 (Brasilia: 2014), 92-108, 94.

Amorina Villareal Brasca, "Gestión política indiana en tiempos de Felipe III: a propósito del patronazgo del duque de Lerma (1598-1618)”, Naveg@mérica, (Revista electrónica editada por la Asociación Española de Americanistas, no. 11, 2013). 